\title{
Assessing Public Preferences for Forest Biomass Based Energy in the Southern United States
}

\author{
Andres Susaeta $\cdot$ Janaki Alavalapati $\cdot$ \\ Pankaj Lal · Jagannadha R. Matta • \\ Evan Mercer
}

Received: 23 August 2009/ Accepted: 13 January 2010

(C) Springer Science+Business Media, LLC 2010

\begin{abstract}
This article investigated public preferences for forest biomass based liquid biofuels, particularly ethanol blends of $10 \%(E 10)$ and $85 \%$ (E85). We conducted a choice experiment study in three southern states in the United States: Arkansas, Florida, and Virginia. Reducing atmospheric $\mathrm{CO}_{2}$, decreasing risk of wildfires and pest outbreaks, and enhancing biodiversity were presented to respondents as attributes of using biofuels. Results indicated that individuals had a positive extra willingness to pay (WTP) for both ethanol blends. The extra WTP was greater for higher blends that offered larger environment benefits. The WTPs for $E 10$ were $\$ 0.56$ gallon $^{-1}$, $\$ 0.58$ gallon $^{-1}$, and $\$ 0.48$ gallon $^{-1}$, and for $E 85$ they were $\$ 0.82$ gallon $^{-1}, \$ 1.17$ gallon $^{-1}$, and $\$ 1.06$ gallon $^{-1}$ in Arkansas, Florida, and Virginia, respectively. Although differences in WTP for E10 were statistically insignificant among the three states, significant differences were found in the WTP for $E 85$ between AR and FL and between AR and VA. Preferences for the environmental attributes appeared to be heterogeneous, as respondents' were willing to pay a premium for $E 10$ in all three states to facilitate the reduction of $\mathrm{CO}_{2}$ and the improvement of biodiversity but
\end{abstract}

A. Susaeta $(\bowtie) \cdot$ P. Lal · J. R. Matta

School of Forest Resources and Conservation, University

of Florida, 374 Newins ZieGler Hall, PO Box 110410,

Gainesville, FL 32611, USA

e-mail: asusaeta@ufl.edu

J. Alavalapati

Department of Forest Resources and Environmental

Conservation, Virginia Polytechnic Institute and

State University, Blacksburg, VA, USA

E. Mercer

USDA Forest Service, Southern Research Station,

Research Triangle Park, NC, USA were not willing to pay more for $E 85$ in order to enhance biodiversity.

Keywords Biofuels - Choice experiment . Willingness to pay

\section{Introduction}

Currently, around $26 \%$ of the total energy used in the United States (U.S.) is imported, and $84 \%$ of the imports are represented by crude oil and petroleum products (EIA 2009). Further, $46 \%$ of the petroleum imports come from the Organization of the Petroleum Exporting Countries (OPEC) (EIA 2009). The transportation sector was the largest consuming sector of petroleum in 2008, at 13.7 million barrels day ${ }^{-1}$ (70\% of all petroleum used), and motor gasoline was the single largest petroleum product consumed (64\% of all petroleum consumption) (EIA 2009). This strong dependency on foreign markets, particularly from volatile Middle East countries, together with concerns about the effects of greenhouse gas (GHG) emissions, have prompted policy makers to find alternative renewable energy sources. Although 53\% of renewable energy consumption comes from biomass-wood, waste and biofuels-biofuels-transportation fuels such as ethanol and biodiesel-represent only $19 \%$ of the total consumption of renewable energy and only $7 \%$ of the total U.S. energy consumption (EIA 2009). Nevertheless, Perlack and others (2005) estimates that the U.S has the potential to displace $30 \%$ of current petroleum consumption with biofuels by 2030, providing a sustainable supply of biomass of more than 1 million dry tons.

Blends of $10 \%(E 10)$ and $85 \%(E 85)$ ethanol with petroleum are the most widely used liquid biofuels in the 
U.S. transportation fuels, accounting for $95 \%$ of total U.S. biofuel consumption (EIA 2009). E10 can be run in any vehicle, while E85 is restricted to Flexible Fuel Vehicles. The main disadvantage are low energy content; E10 and E85 have 3.3 and $24.7 \%$ less energy content per gallon, respectively, than gasoline. This implies that around 1.03 gallons of E10 and 1.33 gallons of E85 are required for a vehicle to cover the same distance that it would cover with 1 gallon of gasoline (EIA 2007). Greenhouse gas emissions per mile traveled, however, are reduced by around 2 and $25 \%$ for corn based E10 and E85 and 10 and 65-90\% for cellulosic based E10 and E85, respectively (Wang and others 1999; Wang 2005).

The purpose of this article is to explore public preferences for biofuels created from forest biomass. Forest based biofuels potentially provide a number of environmental and social benefits including the following: reduction of GHG emissions; reduced soil acidification, improved nitrogen balance, and reduced nutrient leaching (Borjesson 2000); opportunities for forest stand site rehabilitation (Manley and Richardson 1995); improved forest sustainability; increased rural employment; and improved financial returns to landowners (Domac and others 2005; Gan and Smith 2007). Despite the recent policy incentives for producing cellulosic biofuels, questions remain concerning the demand for biofuels and whether the public is willing to pay a premium for forest based biofuels and their associated environmental and social benefits.

A variety of stated preference techniques have been applied to gauge the willingness to pay for renewable energy. A number of studies have focused on the generation of green electricity (Menegaki 2008). For example, Roe and others (2001) projected a median willingness to pay ranging between $\$ 0.38$ and $\$ 5.66$ year $^{-1}$ for green electricity that would decrease GHG emissions by $1 \%$ in the U.S. In Scotland, Bergmann and others (2006) reported that respondents would be willing to pay an additional $£ 14.03$ year $^{-1}$ household $^{-1}$ for renewable energy projects that do not increase air pollution. Solomon and Johnson (2009) used contingent valuation and fair share methods to assess the public's willingness to pay for cellulosic ethanol to mitigate global climate change in the upper Midwestern U.S. They estimated a mean total willingness to pay between \$252-\$556 per capita year ${ }^{-1}$ and a fair share between \$192-\$472 per capita year $^{-1}$.

We employed an online choice experiment (CE) to assess preferences for ethanol blends of $10 \%(E 10)$ and $85 \%$ (E85) in the southern U.S. Web based surveys emerged during the last decade (Champ 2003) due to their low cost, speed, and accuracy in stated preferences studies (Berrens and others 2004; Banzhaf and others 2006; MartaPedroso and others 2007). Although web based surveys provide similar welfare estimates compared to traditional mail surveys (Fleming and Bowden 2007), they have been criticized for problems with sample frame selection and non response bias (Manfreda 2001).

In addition to reducing GHG emissions and improving soil chemistry, we also examined the public's preferences for biodiversity benefits resulting from a reduction of wildfires and pest outbreaks associated with forest based biofuel production. Although fire is a natural component of some forest ecosystems, changes in the dynamic of wildfires and its effects have been considered a major threat to forest biodiversity (Secretariat of the Convention on Biological Diversity 2001). Repeated wildfire can reduce soil fertility, damage the soil structure, and increase soil erosion resulting in declines in water quality (Cochrane and Schulze 1999; Dawson and others 2001). Wildfires can destroy habitats, food trees, and standing cavity tress reducing the carrying capacity of the forest and associated species (Secretariat of the Convention on Biological Diversity 2001). Pest outbreaks can also decrease some forms of biodiversity (Simberloff 1999). For example, southern pine beetle kills pines where red-cockaded woodpeckers nest (Coulson and Stephen 2006). Many argue that conservation, preservation, and fire suppression policies have distorted the effect of natural processes such as wildfires and pest outbreaks in reducing forest biomass. Removal of the resulting excessive forest biomass may enhance forest sustainability and biodiversity and reduce wildfire risk (Richardson 2006). In fact, silvicultural practices such as stand thinnings are commonly used to extract small diameter wood and reduce excessive amounts of forest biomass to improve forest productivity and reduce the risk of wildfire and pest outbreaks (Belanger and others 1993; Speight 1997; Neary and Zieroth 2007).

This article is organized into sixth sections. First, we present a review of the U.S. bioenergy policy. Second, we contrast corn ethanol with cellulosic ethanol production. Then we outline the CE questionnaire and describe the attributes and socioeconomic variables. The fourth section contains descriptions of the econometric model and the welfare estimates. In the fifth section, we report the results and discussion. Lastly, we summarize the main findings.

\section{Bioenergy Policy}

Incentives for liquid biofuels were first instituted in the late 1970s to enhance U.S. energy security. The Energy Tax Act of 1978 provided a $\$ 0.40$ gallon $^{-1}$ exemption from the federal gasoline excise tax for blends with at least $10 \%$ ethanol, which increased to $\$ 0.60$ gallon $^{-1}$ when the Tax Reform Act of 1984 was enacted and then reduced to $\$ 0.51$ gallon $^{-1}$ by the 1998 Transportation Equity Act of the 21st Century. The American Jobs Creation Act of 2004 
replaced the excise tax exemption with a volumetric ethanol excise tax credit of $\$ 0.51$ gallon $^{-1}$ until 2010. Further, a tariff of $\$ 0.54$ gallon $^{-1}$ was imposed on imported ethanol under the purview of the Omnibus Reconciliation Act of 1980 to stimulate domestic industry.

Several other federal policies have been adopted to address environmental concerns about the use of fossil fuels. For example, the Clean Air Act amendment of 1990 established an oxygenated gasoline program to create a new, balanced strategy to address the problems of urban smog and carbon monoxide. The Energy Policy Act of 1992 extended the tax exemption to include blends of 7.7 and 5.7\% ethanol. The Energy Policy Act of 2005 introduced the concept of a Renewable Fuel Standard (RFS) requiring a minimum amount of renewable fuel production, starting with 4 billion gallons in 2006 and achieving 7.5 billion gallons by 2012. After 2012, renewable fuel and gasoline production would grow at the same rate. The Energy Independence and Security Act of 2007 established higher RFSs of 15.5 billion gallons in 2012 and 36 billion gallons by 2022, of which 21 billion gallons must be cellulosic biofuel. Title IX of the 2002 and 2008 Farm Bills established new programs and grants for the procurement of biobased products to support development of biorefineries and assistance to farmers and ranchers in purchasing renewable energy systems.

A number of federal policies, such as the 2002 Farm Bill, 2005 Energy Policy Act, and the 2007 Energy Independence Security Act have specifically encouraged the production of cellulosic ethanol. The Biomass Research and Development Act of 2000 attempted to replace $30 \%$ of petroleum consumption with biofuels produced from agricultural and forest resources. The Healthy Forests Restoration Act of 2003 ( $p$ 198) encouraged communities to use more wood and other plant materials removed through forest health projects as energy feedstocks. The Food, Conservation, and Energy Act of 2008 expanded the renewable energy programs authorized by the 2002 Farm Bill. In its Title IX, it authorized mandatory funding of $\$ 1.1$ billion for the period 2008-2012, providing grants and loans to promote alternative feedstock resources such as switchgrass and woody biomass.

\section{Ethanol Production: Corn Versus Cellulosic Biomass}

The U.S. emerged as the world's leading producer of ethanol (95\% from corn) in 2006 (Hettinga and others 2009, Solomon and others 2007). Corn based ethanol production has been criticized, however, for reducing food security and consequently, increasing prices of related products such as milk, meat, and eggs (Pimentel and Patzek 2005). Several environmental impacts and low (even negative) net energy balance ratios have also been associated with corn based ethanol (Pimentel and Patzek 2005; Hill and others 2005; Solomon and others 2007). Although some predict that food prices will remain high along with higher energy prices (Renewable Fuels Association (RFA 2008), Evans (1998) predicts that as ethanol production expands and new feedstocks materialize, any increase in food prices may be offset by lower energy prices Furthermore, Urbanchuk (2007) argues that the increase in food prices due to higher corn price will only produce half the impact on the Consumer Price Index (CPI) for food as the same percentage increase in energy prices.

Cellulosic biomass for ethanol production, on the other hand, has a higher net energy balance ratio, provides more environmental benefits in terms of GHG reduction, and is potentially cost competitive compared to food-based biofuels (Hill and others 2005). In addition, the use of forest biomass for cellulosic ethanol production could establish markets for currently non commercial harvest residues reducing flammable materials on the forest floor and the risk of wildfires and pest outbreaks while improving the profitability of forest landowners (Neary and Zieroth 2007; Susaeta and others 2009). However, careful consideration must be given to managing forests intensively for bioenergy purposes. Without appropriate planning, optimal harvest systems, and maintaining the connectivity of habitat networks, the production of bioenergy could lead to a loss of biodiversity (Cook and others 1991).

\section{Study Design and Data Collection}

\section{CE Questionnaire}

We employed a survey based choice experiment (CE), to elicit the public's preferences for transportation biofuels. Our web based survey of households in Arkansas (AR), Florida (FL), and Virginia (VA) was administered and hosted by Knowledge Networks (KN). KN was founded in 1998 seeking to develop online research methodologies, and established the first online research panel-KnowledgePanel—based on probability sampling covering online and offline populations in the U.S. Since households, selected with random digit dialing (RDD), were provided access to the internet and hardware if needed, our sample was not limited to web users or computer owners. Once a person decided to join the panel, she/he was sent a survey by email. KN sample design is an equal probability sample design that is self weighting. To correct for potential oversampling of minorities or households with access to the internet and subsampling of telephone numbers without an address, adjustments to the geographic frame-to areas with larger concentrations of African Americans and 
Hispanics to increase their panel membership-and language were incorporated into the base weights.

To minimize non response bias, subjects were encouraged to participate through incentives, newsletters, and other techniques (e.g., a toll free helpline for providing assistance with survey questions). In addition, non respondents were re-contacted several times. Lastly, the final data set was post-stratified using current demographic distributions from the Current Population Survey (CPS) as benchmarks to adjust for non response bias and non coverage (Huggins and others 2002). A random sample of 630 households drawn from the $\mathrm{KN}$ online research panel that met the criteria of being in the general population and over 18 years old received the questionnaire in March and April 2008.

The questionnaire contained two parts, the CE section and a section eliciting information about the respondents' socioeconomic conditions. In the CE section, respondents were asked to choose between two alternative plans, Plan A, purchasing biofuels to reduce GHG emissions and improve biodiversity and Plan B, no change in current fuel consumption. The first part of the $\mathrm{CE}$ questionnaire informed respondents about the benefits producing ethanol from forest biomass, i.e., reduced GHG emissions, reduced loss of biodiversity due to reduced risk of wildfires and pest outbreaks. Biodiversity was informally explained in terms of species variety-particularly trees and animals-and their abundance. A "cheap talk script" was incorporated in the design to avoid a common problem of stated preference experiments (i.e., the difference between stated and actual behavior) (Cummings and Taylor 1999; List 2001; Menges and others 2005; Carlsson and others 2005). The attributes and their respective levels were explained to respondents, and an example was provided to facilitate comprehension. Respondents were then asked to provide their views about bioenergy and outline their stated preferences.

Respondents were presented only one questionnaire, regarding the use of either $E 85$ or $E 10$. The attributes were: (1) reduced $\mathrm{CO}_{2}$ emission per mile traveled, (2) reduced probability of biodiversity loss by decreasing wildfires and pest outbreaks, and (3) increased price of fuel at the pump.
A brief description of the attributes and their levels is given in Table 1. The three attributes and their respective levels provided 36 possible combinations $\left(3^{2} \times 4^{1}\right)$ for Plan A, achieving a $100 \%$ A-efficiency. A-Efficiency refers to a measure of the goodness of the experimental design and is a function of the arithmetic mean of the variances given by trace of $\left(X^{\prime} X\right)^{-1} / p$, where $X$ is the coded design and $p$ is the number of columns of the inverse of the information matrix $X^{\prime} X$ (Kuhfeld 2005). Because it is not practical to ask a respondent to answer 36 different CE questions, we applied an orthogonal full factorial experiment design to produce six different versions of the questionnaire, each having six pair wise alternative plans. Thus, each respondent received one questionnaire with six sets of $\mathrm{CE}$ questions, each consisting of two plans, Plan A and Plan B, representing six different observations. Six CE questions is in accordance with previous CE studies, which have found that a range of 4-12 alternative plans avoid violating the assumption of stability of preferences (Hanemann 1984; Carlsson and others 2003; Shresta and Alavalapati, 2004; Mogas and others 2006). The SAS 9.1\%MKTRuns and $\%$ MktEx macros were used to determine the number of alternative plan sets and the linear design (Kuhfeld 2005).

Table 2 presents an example of the alternative plan presented to respondents. The valuation question in this example is:

Are you willing to pay an extra $\$ 0.60$ per gallon at the pump for reducing the $\mathrm{CO}_{2}$ emissions between $61-70 \%$ (medium reduction) and improving the biodiversity between 1-25\% (low improvement) (Plan A) or not to pay a premium at all without having any changes in $\mathrm{CO}_{2}$ emissions and biodiversity improvement (Plan B).

The attributes were based on a literature review regarding forest based bioenergy (Farnsworth and others 2003; Gan 2007; Polagye and others 2007) and discussions with stakeholders and experts from academia, industry, and nongovernmental organizations specializing in forest biomass research. Two focus groups of 12 people each-
Table 1 Description of the attributes and levels

\begin{tabular}{|c|c|c|c|}
\hline \multirow[t]{2}{*}{ Attribute } & \multirow[t]{2}{*}{ Description } & \multicolumn{2}{|l|}{ Level } \\
\hline & & E10 & E85 \\
\hline $\operatorname{Reco} 2$ & $\begin{array}{l}\text { Percentage reduction of } \mathrm{CO}_{2} \text { emissions } \\
\text { (per mile traveled) }\end{array}$ & $\begin{array}{l}1-3 \% \text { (low) } \\
4-7 \% \text { (medium) } \\
8-10 \% \text { (high) }\end{array}$ & $\begin{array}{l}1-60 \% \text { (low) } \\
61-70 \% \text { (medium) } \\
71-90 \% \text { (high) }\end{array}$ \\
\hline Biomp & $\begin{array}{l}\text { Percentage improvement of biodiversity } \\
\text { by reducing wildfire risk and improving } \\
\text { forest health }\end{array}$ & $\begin{array}{l}1-20 \% \text { (low) } \\
21-40 \% \text { (medium) } \\
41-60 \% \text { (high) }\end{array}$ & $\begin{array}{l}1-25 \% \text { (low) } \\
26-50 \% \text { (medium) } \\
51-75 \% \text { (high) }\end{array}$ \\
\hline Prem & $\begin{array}{l}\text { Increase of the price of fuel at the pump } \\
\text { per gallon }\end{array}$ & $\$ 0.2, \$ 0.5, \$ 0.75, \$ 1$ & $\$ 0.3, \$ 0.6, \$ 1, \$ 1.5$ \\
\hline
\end{tabular}


Table 2 Description of the choice situation

\begin{tabular}{lll}
\hline Please choose & Plan A & Plan B \\
\hline Reco2 & $\begin{array}{c}\text { Reduction of } \mathrm{CO}_{2} \text { between } \\
61-70 \% \text { per mile traveled }\end{array}$ & No reduction $(0 \%)$ \\
& $\begin{array}{l}\text { Improvement of biodiversity } \\
\text { biomp }\end{array}$ & No improvement $(0 \%)$ \\
& between 1-25\% & \\
Prem & Additional payment of $\$ 0.60$ & No extra payment (\$0) \\
& per gallon at the pump & \\
\hline
\end{tabular}

randomly selected and contacted by phone-followed by a pilot survey were used to develop the final list of attributes and their levels. Although Plan A is described in terms of attributes and their levels in our study, we focus on the WTP for improving environmental quality rather than valuing individual attributes. Plan B allowed respondents to choose the status quo.

The levels of percentage reduction of $\mathrm{CO}_{2}$ depend on the energy and chemical usage intensity of biomass farming, ethanol yield per dry ton of biomass, and electricity credits in cellulosic ethanol plants (Wang and others 1999; Wang 2005). To facilitate respondent understanding of the attribute levels, we linked each level of reduction of $\mathrm{CO}_{2}$ emission to a non numerical category: low, medium or high. Catastrophic disturbance rates in forests are generally around $1 \%$ annually, ranging from 0.5 to $2 \%$ (Runkle 1985). The levels of reduction of pest outbreaks and wildfires were based on existing literature (Agee and others 2000; Fettig and others 2006; Susaeta and others 2009). Again, each level of reduction was linked to a non numerical category: low, medium, or high. We assumed a higher price premium for $E 85$ based on higher environmental benefits and lower energy content per gallon. Since the decision to pay a premium for biofuels is influenced by current market fuel prices (Aguilar and Vlosky 2007), a reference price of gasoline was provided to respondents decision. For AR, FL, and VA the average gasoline prices were $\$ 3.45$ gallon $^{-1}$, \$3.63 gallon ${ }^{-1}$ and $\$ 3.69$ gallon $^{-1}$, respectively (http://e85prices.com/archive.php). Socioeconomic variables elicited in the second section are described in Table 3. Non automobile owners, expected to be few in number, were included in the survey because they might also be interested in purchasing biofuels.

\section{Econometric Model}

The theoretical framework to analyze the CE method is based on random utility theory in which the indirect utility of an individual is the sum of a deterministic part and a stochastic element McFadden (1974). Formally:

$U_{i j}=V_{i j}+\varepsilon_{i j}$

where $U_{i j}$ is the utility for each respondent $i$ to choose among different $j$ alternatives, $V_{i j}$ is the deterministic part of the utility, and $\varepsilon_{i j}$ reflects unobservable influences on respondent choice. With two alternatives, the individual chooses alternative $j$, which reflects an improved state, over alternative $k$ (status quo) if the utility associated with alternative $j$ exceeds the utility of alternative $k$. The probability that individual $i$ will choose alternative $j$ over $k$ is:
Table 3 Socioeconomic variables

\begin{tabular}{ll}
\hline Variable & Description \\
\hline Member & $\begin{array}{l}\text { Membership in an environmental organization: } 1 \text { if respondent is a member and } \\
0 \text { otherwise } \\
\text { Knowledge of other natural resources based energy: } 1 \text { if respondent knows and } \\
0 \text { otherwise } \\
\text { Onowledge }\end{array}$ \\
Ownership & Years \\
Age & Distance driven weekly (miles) \\
Miles week & Less high: 1 if respondent has exclusively less than high school level and 0 otherwise \\
Education & High: 1 if respondent has exclusively high school level and 0 otherwise \\
& Some college: 1 if respondent has exclusively some college level and 0 otherwise \\
& Bachelor: 1 if respondent has exclusively bachelor degree or higher level and \\
& 0 otherwise \\
Income & Lincome: 1 if household Annual Income is less than $\$ 24,9999$ and 0 otherwise \\
& Mincome: 1 if household Annual Income is between $\$ 25,000-\$ 74,999$ and 0 otherwise \\
Hincome: 1 if Household Annual Income is greater than $\$ 75,000$ and 0 otherwise \\
Work
\end{tabular}


$P_{i j}=P\left(V_{i j}+\varepsilon_{i j}\right)>P\left(V_{j k}+\varepsilon_{i k}\right), \quad j \neq k$

Following Haab and McConnell (2002) hereafter, we assumed a linear utility function in income and covariates. Although not conclusive, linear utility functions are a reasonable assumption for decision making processes (Dijkstra and others 1990). The deterministic part of the indirect utility function for an individual $i$ can be written as:

$V_{i j}\left(y_{i}\right)=\alpha_{j} z_{i}+\beta_{j} y_{i}$

where $y_{i}$ is the income of individual $i$ and $z_{i}$ is the matrix of attributes and socioeconomic characteristics of individual $i$, and $\alpha_{j}$ and $\beta_{j}$ are the multidimensional vector and the marginal utility of income of alternative $j$, respectively.

Our dichotomous choice experiment requires each individual to choose between alternative $j$ paying an amount $t_{j}$ and the status quo. Thus, the deterministic parts of the utility function for alternatives $j$ and $k$ are:

$$
\begin{aligned}
& V_{i j}\left(y_{i}-t_{j}\right)=\alpha_{j} z_{i}+\beta_{j}\left(y_{i}-t_{j}\right) \\
& V_{i k}\left(y_{i}\right)=\alpha_{k} z_{i}+\beta_{k}\left(y_{i}\right)
\end{aligned}
$$

Replacing (4) and (5) into (2) and rearranging, we obtain the following expressions:

$$
P\left(\text { yes }_{i}\right)=P\left(\alpha_{j} z_{i}+\beta_{j}\left(y_{i}-t_{j}\right)+\varepsilon_{i j}\right)>P\left(\alpha_{k} z_{i}+\beta_{k}\left(y_{i}\right)+\varepsilon_{i k}\right)
$$

$$
\begin{aligned}
P\left(\text { yes }_{i}\right)= & P\left(\alpha_{k}-\alpha_{j}\right) z_{i}+\beta_{j}\left(y_{i}-t_{j}\right)-\beta_{k}\left(y_{i}\right)+\varepsilon_{i j} \\
& \left.-\varepsilon_{j k}\right)>0
\end{aligned}
$$

Assuming that the marginal utility of income is constant and denoting $\propto=\alpha_{k}-\alpha_{j}$ and $\varepsilon_{i}=\varepsilon_{i j}-\varepsilon_{i k}$, the probability of a yes response is:

$P\left(\right.$ yes $\left._{i}\right)=P\left(\alpha z_{i}+\beta t_{j}+\varepsilon_{i}\right)>0$

Assuming that $\varepsilon_{i} \sim N\left(0, \sigma^{2}\right)$ and converting the errors to a standard normal, we obtain the probit model:

$P\left(\right.$ yes $\left._{i}\right)=\varphi\left(\alpha z_{i} / \sigma-\beta t_{j} / \sigma\right)$

Estimates for the parameters $\propto / \sigma, \beta / \sigma$, are obtained by maximizing the likelihood function. In the case of a probit model, the log likelihood function takes the following form:

$$
\begin{aligned}
\ln L\left(\frac{\alpha}{\sigma}, \frac{\beta}{\sigma} \mid y, z_{i}, t_{j}\right)= & \sum_{i=1}^{T} I_{i} \ln \left[\left(\varphi\left(\alpha z_{i} / \sigma-\beta t_{j} / \sigma\right)\right)\right] \\
& +\left(1-I_{i}\right) \ln \left[1-\varphi\left(\alpha z_{i} / \sigma-\beta t_{j} / \sigma\right)\right]
\end{aligned}
$$

where $\mathrm{T}$ is the sample size and $I_{i}=1$ if individual $i$ answers yes.
We assumed that the attributes and the socioeconomic variables of this discrete choice model were exogenous, i.e., determined outside of the model. However, distance driven per week may be correlated with the error term (endogenously determined). If endogeneity arises for this particular case, the estimated coefficient of weekly mileage will be upwardly or downwardly biased depending on the direction of the correlation with the error terms. Potential solutions to correct for endogeneity are the use of instrumental variables or the determination of the endogenous variable by an equilibrium model (Besanko and others 1998). However, correction for endogeneity bias is beyond the purview of this article.

\section{Welfare Estimates}

Two measures of central tendency were developed by Hanemann (1984), the expected WTP [E(WTP)] and the median WTP $[\operatorname{Md}(\mathrm{WTP})]$, which are equal under the assumption of a linear utility function. Thus,

$E(W T P)=M d(W T P)=\alpha \bar{z} / \beta$

where $\bar{z}$ is the mean of attributes and socioeconomic characteristics.

\section{Results and Discussion}

A total of 408 questionnaires were completely answered (65\% response rate), 201 questionnaires regarding E10 (56 in AR, 76 in FL, and 69 in VA) and 207 questionnaires for $E 85$ (53 in AR, 79 in FL, and 74 in VA). We used STATA 9.0 to estimate separate probit models for E10 and E85. Tables 4 and 5 present the descriptive statistics for the socioeconomic variables of the E10 and E85 samples, respectively. Generally, respondents were not part of any environmental organization, had achieved one of the two highest levels of education, and owned an automobile. Further, respondents belonged mainly to the middle income category, with the exception of E10 respondents in VA.

Consistent with expectations, respondents were less likely to accept the premium as the price increased (Figs. 1, 2). Regardless of the premium level, the average relative decrease for a yes response was around $10 \%$ in each state for $E 10$. In the case of $E 85$, the average relative decrease amounted to $15.1,9$, and $8.6 \%$ for AR, FL, and VA, respectively. The majority of the respondents were willing to pay a premium for both blends in FL and for only E85 in AR. In VA, the majority of the respondents were not willing to pay a premium for either E10 or E85. 
Table 4 Descriptive statistics for socioeconomic variables, E10

\begin{tabular}{|c|c|c|c|c|c|c|c|c|c|c|c|c|}
\hline \multirow[t]{2}{*}{ Variable } & \multicolumn{4}{|l|}{$\mathrm{AR}$} & \multicolumn{4}{|l|}{ FL } & \multicolumn{4}{|l|}{ VA } \\
\hline & Mean & SD & Min & Max & Mean & SD & Min & Max & Mean & SD & Min & Max \\
\hline Member & 0.05 & 0.23 & 0 & 1 & 0.11 & 0.31 & 0 & 1 & 0.12 & 0.32 & 0 & \\
\hline Knowledge & 0.46 & 0.50 & 0 & 1 & 0.54 & 0.50 & 0 & 1 & 0.49 & 0.50 & 0 & \\
\hline Ownership & 0.98 & 0.13 & 0 & 1 & 0.89 & 0.31 & 0 & 1 & 0.90 & 0.30 & 0 & 1 \\
\hline Miles week & 169.3 & 142.7 & 0 & 750 & 121 & 102.4 & 0 & 420 & 168.4 & 179.7 & 0 & 1,100 \\
\hline Age & 51.9 & 12.8 & 22 & 76 & 52.3 & 17 & 18 & 81 & 46.7 & 15.4 & 20 & 89 \\
\hline Less high & 0 & 0 & 0 & 1 & 0.08 & 0.27 & 0 & 1 & 0.06 & 0.23 & 0 & 1 \\
\hline High & 0.21 & 0.41 & 0 & 1 & 0.26 & 0.44 & 0 & 1 & 0.30 & 0.46 & 0 & 1 \\
\hline College & 0.34 & 0.47 & 0 & 1 & 0.34 & 0.47 & 0 & 1 & 0.32 & 0.47 & 0 & 1 \\
\hline Bachelor & 0.45 & 0.50 & 0 & 1 & 0.32 & 0.47 & 0 & 1 & 0.32 & 0.47 & 0 & 1 \\
\hline Gender & 0.41 & 0.49 & 0 & 1 & 0.45 & 0.50 & 0 & 1 & 0.46 & 0.50 & 0 & 1 \\
\hline Head & 0.93 & 0.26 & 0 & 1 & 0.92 & 0.27 & 0 & 1 & 0.87 & 0.34 & 0 & 1 \\
\hline Lincome & 0.14 & 0.35 & 0 & 1 & 0.21 & 0.41 & 0 & 1 & 0.17 & 0.38 & 0 & 1 \\
\hline Mincome & 0.63 & 0.48 & 0 & 1 & 0.51 & 0.50 & 0 & 1 & 0.35 & 0.48 & 0 & 1 \\
\hline Hincome & 0.23 & 0.42 & 0 & 1 & 0.28 & 0.45 & 0 & 1 & 0.48 & 0.50 & 0 & 1 \\
\hline Size & 2.39 & 1.31 & 1 & 6 & 2.30 & 1.40 & 1 & 9 & 2.65 & 1.26 & 1 & 6 \\
\hline Work & 0.64 & 0.48 & 0 & 1 & 0.43 & 0.50 & 0 & 1 & 0.67 & 0.47 & 0 & 1 \\
\hline Number of observations & 330 & & & & & 456 & & & 414 & & & \\
\hline
\end{tabular}

Table 5 Descriptive statistics for socioeconomic variables, E85 sample

\begin{tabular}{|c|c|c|c|c|c|c|c|c|c|c|c|c|}
\hline \multirow[t]{2}{*}{ Variable } & \multicolumn{4}{|l|}{$\mathrm{AR}$} & \multicolumn{4}{|l|}{ FL } & \multicolumn{4}{|l|}{ VA } \\
\hline & Mean & SD & Min & $\operatorname{Max}$ & Mean & SD & Min & $\operatorname{Max}$ & Mean & SD & Min & Max \\
\hline Member & 0.04 & 0.19 & 0 & 1 & 0.06 & 0.24 & 0 & 1 & 0.07 & 0.25 & 0 & 1 \\
\hline Knowledge & 0.43 & 0.50 & 0 & 1 & 0.43 & 0.50 & 0 & 1 & 0.39 & 0.49 & 0 & 1 \\
\hline Ownership & 0.96 & 0.19 & 0 & 1 & 0.92 & 0.27 & 0 & 1 & 0.99 & 0.12 & 0 & 1 \\
\hline Miles week & 128.8 & 127.3 & 0 & 580 & 132.3 & 126.4 & 0 & 500 & 158.5 & 146.4 & 0 & 750 \\
\hline Age & 53.1 & 14.6 & 21 & 87 & 51.1 & 18.9 & 19 & 89 & 45.4 & 15.1 & 18 & 81 \\
\hline Less high & 0.02 & 0.14 & 0 & 1 & 0.10 & 0.30 & 0 & 1 & 0.07 & 0.25 & 0 & 1 \\
\hline High & 0.13 & 0.34 & 0 & 1 & 0.24 & 0.43 & 0 & 1 & 0.31 & 0.46 & 0 & 1 \\
\hline College & 0.42 & 0.49 & 0 & 1 & 0.37 & 0.48 & 0 & 1 & 0.26 & 0.44 & 0 & 1 \\
\hline Bachelor & 0.43 & 0.50 & 0 & 1 & 0.29 & 0.45 & 0 & 1 & 0.36 & 0.48 & 0 & 1 \\
\hline Gender & 0.36 & 0.48 & 0 & 1 & 0.82 & 0.38 & 0 & 1 & 0.45 & 0.50 & 0 & 1 \\
\hline Head & 0.94 & 0.23 & 0 & 1 & 0.47 & 0.50 & 0 & 1 & 0.92 & 0.27 & 0 & 1 \\
\hline Lincome & 0.21 & 0.41 & 0 & 1 & 0.27 & 0.44 & 0 & 1 & 0.12 & 0.33 & 0 & 1 \\
\hline Mincome & 0.53 & 0.50 & 0 & 1 & 0.43 & 0.50 & 0 & 1 & 0.53 & 0.50 & 0 & 1 \\
\hline Hincome & 0.26 & 0.44 & 0 & 1 & 0.30 & 0.46 & 0 & 1 & 0.35 & 0.48 & 0 & 1 \\
\hline Size & 2.30 & 1.19 & 1 & 5 & 2.30 & 1.37 & 1 & 6 & 2.43 & 1.30 & 1 & 7 \\
\hline Work & 0.53 & 0.50 & 0 & 1 & 0.55 & 0.50 & 0 & 1 & 0.68 & 0.47 & 0 & 1 \\
\hline Number of observations & 306 & & & & 474 & & & & 444 & & & \\
\hline
\end{tabular}

\section{Attributes}

Tables 6 and 7 show the coefficients, $P$ values, and standard deviations of the estimated probit models in AR, FL, and VA for E10 and E85, respectively. The log likelihood ratios $(P<0.001)$ suggested that the overall models for both blends were statistically significant in all three states.

STATA routines dropped variables that perfectly predicted success or failure in the dependent variable. For E10, all respondents owned a car in AR; thus, this dummy 


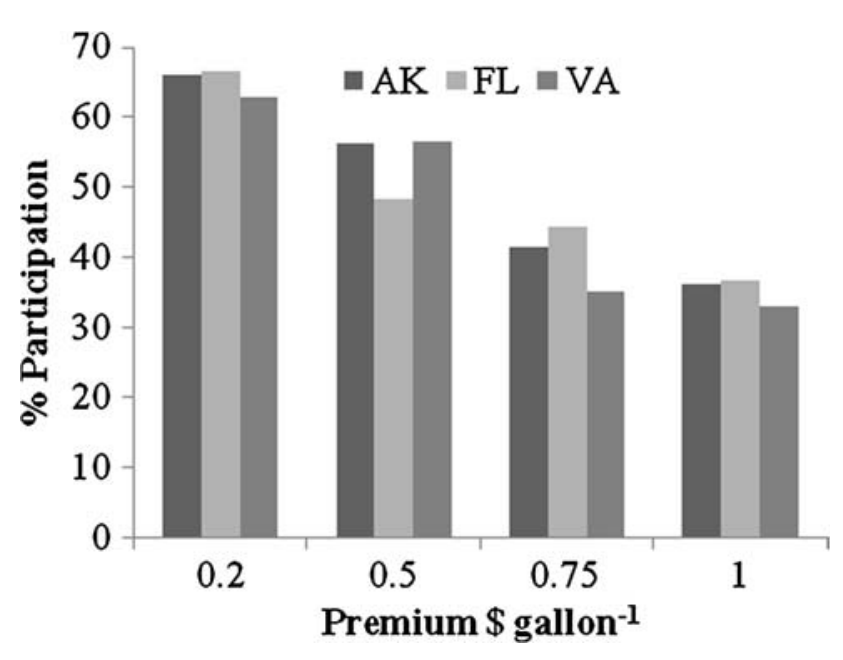

Fig. 1 Percentage of yes responses for E10

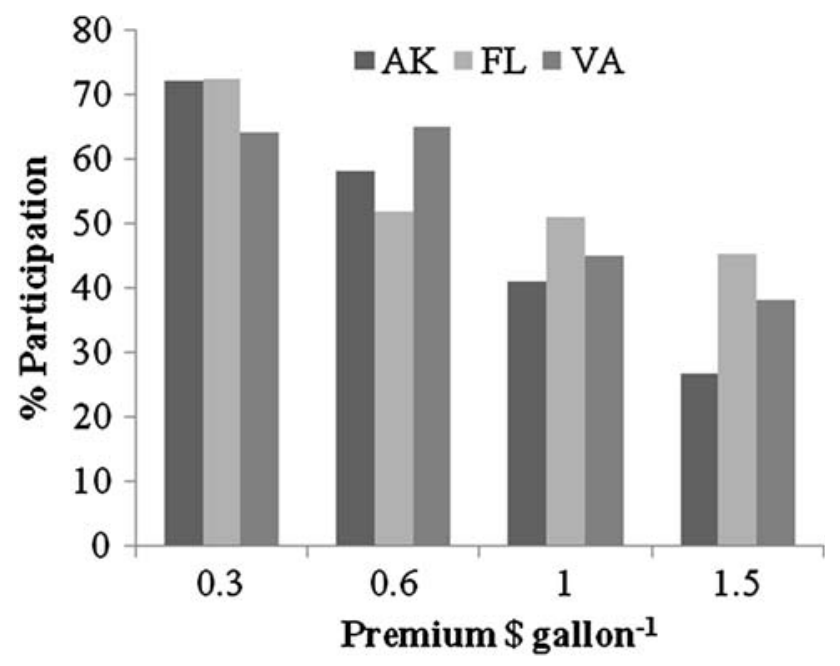

Fig. 2 Percentage of yes responses for E85

variable only took the value of 1 , showing no variation across the sample. In the case of educational variables, Less high was not included in the model to avoid the dummy variable trap. However, this variable only took the value of 0 in AR, as all respondents had some high school level. Thus, College was dropped to avoid collinearity. For E85 Member in AR and Ownership in VA were dropped. Almost none of the respondents were members of an environmental organization, and almost all owned an automobile.

Consistent with economic theory under the assumption of a negative price elasticity of demand-a percent change in the quantity demanded given a percent change in pricethe utility of individuals decreased as the premium increased for either blend and was statistically significant in all three states. In response to questions concerning E10, the coefficient of the attribute "Percentage reduction of $\mathrm{CO}_{2}$ emissions" (Reco2) was positive in all three states but only statistically significant in FL and VA. Likewise, "Percentage improvement of Biodiversity" (Biomp) was positive in AR and FL but was not statistically significant. This indicates that the probability of paying a premium increased as the reduction of $\mathrm{CO}_{2}$ increased and biodiversity conditions improved. Results differed when the choice concerned E85. Respondents from AR and VA were less likely to use $E 85$, and Reco2, which was significant only in AR, had negative coefficients in AR and VA, while the variable Biomp -although statistically insignificant in all states-had negative coefficients in all three states.

The probability of paying a premium for $E 10$ increased in all three states as reductions in $\mathrm{CO}_{2}$ increased or biodiversity improved. These results were consistent with previous studies which found that when environmental quality improved, the utility of respondents increased, and therefore they were willing to pay more for green electricity (Roe and others 2001; Bergmann and others 2006). However, the same trend was not observed in the E85 scenario, as respondents declined to pay a premium for reducing $\mathrm{CO}_{2}$ in AR or improving biodiversity in all states at higher rates. Nevertheless, except for the variable Reco 2 in VA, the results for $E 85$ fuel were consistent with the probabilities of the model for the environmental attributes (Table 8).

Socioeconomic Variables

\section{Member, Knowledge, Ownership, and Miles Week}

Neither the condition of being a "Member of an environmental organization" (Member) nor having "Knowledge of other natural resources based energy" (Knowledge) were statistically significant in any of the states for E10. For E85, however, Member was significant only in AR, and Knowledge was significant only in VA. Further, the likelihood of switching to biofuels increased if respondents were members of an environmental organization in AR and VA for E10 and in VA for E85. Similar behavior was observed for E85 respondents in AR who were aware of other options for green energy. In the case of the variable "Ownership of an automobile" (Ownership), this probability increased only for E85 and was significant in AR and FL. However, preferences of automobile owners and non automobile owners differed. The percentage of non automobile owners who chose to use E10 was $100 \%$ in AR, $50 \%$ in FL, and $64 \%$ in VA. These percentages were lower for $E 85$ in AR and FL (17 and 25\%, respectively), while in VA $100 \%$ of non automobile owners chose to use biofuels. The variable "Distance driven weekly" (Miles week) was significant when deciding whether to switch to biofuels. For E10, the probability of switching to biofuels increased in FL and decreased in VA. However, Miles week was not significant in any of the states for E85. 
Table 6 Probit model results for E10 sample
$*, * *, * * *$ Denote significant at 10,5 and $1 \%$, respectively

\begin{tabular}{|c|c|c|c|c|c|c|}
\hline \multirow[t]{2}{*}{ Variable } & \multicolumn{2}{|l|}{$\mathrm{AR}$} & \multicolumn{2}{|l|}{ FL } & \multicolumn{2}{|l|}{ VA } \\
\hline & Coefficients & Std & Coefficients & Std & Coefficients & Std \\
\hline $\operatorname{Reco} 2$ & 0.020 & 0.102 & $0.261 * * *$ & 0.092 & $0.262 * * *$ & 0.095 \\
\hline Biomp & 0.159 & 0.107 & 0.020 & 0.093 & -0.009 & 0.01 \\
\hline Prem & $-0.973 * * *$ & 0.322 & $-0.883 * * *$ & 0.267 & $-0.962 * * *$ & 0.310 \\
\hline Member & 0.465 & 0.430 & -0.180 & 0.266 & 0.409 & 0.277 \\
\hline Knowledge & -0.238 & 0.211 & -0.191 & 0.142 & -0.223 & 0.179 \\
\hline Ownership & n.a & n.a & $-1.146^{* * *}$ & 0.315 & -0.320 & 0.305 \\
\hline Miles week & -0.0002 & 0.001 & $0.002 * * *$ & 0.001 & $-0.002 * * *$ & 0.000 \\
\hline Age & $-0.017 * * *$ & 0.009 & 0.000 & 0.006 & 0.010 & 0.007 \\
\hline High & $0.718 * * *$ & 0.239 & $1.267 * * *$ & 0.445 & -0.341 & 0.315 \\
\hline College & n.a & n.a & $1.705 * * *$ & 0.391 & 0.570 & 0.377 \\
\hline Bachelor & -0.050 & 0.269 & $2.095 * * *$ & 0.427 & -0.134 & 0.396 \\
\hline Gender & $0.528 * *$ & 0.207 & $-0.572 * * *$ & 0.151 & $-0.355^{*}$ & 0.210 \\
\hline Head & 0.302 & 0.351 & $1.767 * * *$ & 0.344 & -0.423 & 0.267 \\
\hline Mincome & -0.093 & 0.278 & $0.409 *$ & 0.230 & -0.214 & 0.241 \\
\hline Hincome & $-0.763 * *$ & 0.368 & $0.660 * * *$ & 0.239 & 0.188 & 0.282 \\
\hline Size & $-0.205^{* *}$ & 0.083 & 0.118 & 0.074 & $-0.236^{* * *}$ & 0.074 \\
\hline Work & -0.140 & 0.209 & 0.001 & 0.189 & 0.029 & 0.252 \\
\hline Intercept & $1.393 *$ & 0.829 & $-2.848 * * *$ & 0.774 & $1.352^{*}$ & 0.775 \\
\hline Number of observations & 330 & & 456 & & 414 & \\
\hline Log likelihood & -186.7 & & -227.3 & & -237.84 & \\
\hline Log likelihood ratio & 67.34 & & 129.9 & & 86.47 & \\
\hline$P$ value & 0.00 & & 0.00 & & 0.00 & \\
\hline Pseudo $\mathrm{R}^{2}$ & 0.178 & & 0.278 & & 0.172 & \\
\hline
\end{tabular}

\section{Education}

Effects of educational background differed in the three states. The variable "Respondent with exclusively high school level" (High) was statistically significant and positive, "Respondent with exclusively bachelor degree or higher" (Bachelor) was not statistically significant, and "Respondent with some college level" (College) was significant for E10 in AR. However, in AR and FL, the likelihood of choosing E85 and E10 increased for individuals who had higher education levels, respectively. In VA, no education variables were statistically significant for E10. Individuals with some high school or bachelor's degrees were less likely to pay a premium, but individuals with some college education were more likely to use the E10 blend. Individuals with high school in FL and some college education in VA showed no intention of using E85.

\section{Income}

Income was another variable that showed heterogeneity in individuals' perceptions about biofuels. In AR, only the variable "Households with high income" (Hincome) was statistically significant for both biofuels. Contrary to expectations, the probability of paying a premium decreased as an individual had greater earnings. Although this is inconsistent with economic theory, respondents might have considered exogenous factors such as the unfavorable economic situation prevailing in the country during the time the survey was conducted.

In FL, the variables "Households with middle income" (Mincome) and Hincome were both statistically significant as compared to the lowest income level for E10. Although this situation was not observed for E85, the utility of choosing any of the biofuel blends appeared to increase with increasing income. In VA, no income variables were statistically significant for E10. However, for E85, the middle income category showed significant differences compared to low income individuals.

\section{Age, Gender, and Work}

Age was significant only in AR for E10 and E85. Further, as AR respondents aged they would only be likely to choose E10. On the other hand, Gender was statistically significant in all three states for E10, and in FL and in VA for E85. The probability that females would choose either blend was lower compared to males in FL. The variable 
Table 7 Probit model results for E85 sample
$*, * * * * * *$ Denote significant at 10,5 and $1 \%$, respectively

Table 8 Probabilities of using biofuels for level of environmental attributes at state level

\begin{tabular}{|c|c|c|c|c|c|c|}
\hline \multirow[t]{2}{*}{ Variable } & \multicolumn{2}{|l|}{$\mathrm{AR}$} & \multicolumn{2}{|l|}{ FL } & \multicolumn{2}{|l|}{ VA } \\
\hline & Coefficients & Std & Coefficients & Std & Coefficients & Std \\
\hline Reco2 & $-0.441 * * *$ & 0.156 & 0.073 & 0.087 & -0.005 & 0.082 \\
\hline Biomp & -0.017 & 0.161 & -0.053 & 0.090 & -0.012 & 0.082 \\
\hline Prem & $-1.431 * * *$ & 0.227 & $-0.508 * * *$ & 0.163 & $-0.803 * * *$ & 0.153 \\
\hline Member & n.a & n.a & -0.521 & 0.335 & 0.293 & 0.295 \\
\hline Knowledge & 0.310 & 0.194 & -0.004 & 0.170 & $-0.316^{*}$ & 0.167 \\
\hline Ownership & $2.936 * * *$ & 0.738 & $1.532 * * *$ & 0.309 & n.a & n.a \\
\hline Miles week & $-4.14 \mathrm{E}-06$ & 0.0008 & 0.0003 & 0.0006 & $-3.2 \mathrm{E}-05$ & 0.0005 \\
\hline Age & $0.055 * * *$ & 0.010 & 0.007 & 0.005 & -0.006 & 0.006 \\
\hline High & $3.281 * * *$ & 0.636 & -0.037 & 0.287173 & -0.181 & 0.289 \\
\hline High & $1.614 * * *$ & 0.493 & 0.179 & 0.289 & -0.056 & 0.290 \\
\hline Bachelor & $1.870 * * *$ & 0.516 & 0.404 & 0.285 & 0.0148 & 0.304 \\
\hline Gender & 0.320 & 0.213 & $-0.465 * * *$ & 0.155 & $0.287 * *$ & 0.143 \\
\hline Head & $-1.501 * * *$ & 0.414 & $-0.733 * * *$ & 0.206 & 0.400 & 0.315 \\
\hline Mincome & -0.187 & 0.309 & 0.258 & 0.193 & $-0.463^{*}$ & 0.245 \\
\hline Hincome & $-0.702^{*}$ & 0.386 & 0.266 & 0.211 & -0.285 & 0.252 \\
\hline Size & $0.349 * * *$ & 0.099 & -0.081 & 0.059 & 0.073 & 0.058 \\
\hline Work & $0.569 * *$ & 0.257 & -0.139 & 0.167 & -0.07 & 0.190 \\
\hline Intercept & $-5.234 * * *$ & 1.141 & -0.559 & 0.540 & $1.055^{* *}$ & 0.512 \\
\hline Number of observations & 306 & & 474 & & 438 & \\
\hline Log likelihood & -144.1 & & -275.8 & & -272.8 & \\
\hline Log likelihood ratio & 114.4 & & 88.8 & & 43.36 & \\
\hline$P$ value & 0.00 & & 0.00 & & 0.00 & \\
\hline Pseudo $\mathrm{R}^{2}$ & 0.316 & & 0.16 & & 0.09 & \\
\hline
\end{tabular}

\begin{tabular}{lllllllll}
\hline Attribute & \multicolumn{3}{l}{ E10 } & \multicolumn{7}{c}{ E85 } \\
\hline Reco2 & Level & AR & FL & VA & Level & AR & FL & VA \\
& $1-3 \%$ & 0.476 & 0.382 & 0.367 & $1-60 \%$ & 0.667 & 0.534 & 0.573 \\
& $4-7 \%$ & 0.491 & 0.484 & 0.468 & $61-70 \%$ & 0.520 & 0.563 & 0.577 \\
& $8-10 \%$ & 0.506 & 0.588 & 0.573 & $71-90 \%$ & 0.370 & 0.592 & 0.580 \\
Biomp & $1-20 \%$ & 0.429 & 0.481 & 0.453 & $1-25 \%$ & 0.530 & 0.585 & 0.583 \\
& $21-40 \%$ & 0.490 & 0.489 & 0.449 & $26-50 \%$ & 0.520 & 0.564 & 0.577 \\
& $41-60 \%$ & 0.551 & 0.497 & 0.445 & $51-75 \%$ & 0.510 & 0.543 & 0.570 \\
\hline
\end{tabular}

"Respondent was working" (Work) was insignificant in all three states for E10 and significant only in AR for E85. Furthermore, individuals would continue using cheaper fuel if they were unemployed in AR for E10 and FL and VA for $E 85$.

\section{Size, Head, and Intercept}

The "Size of the household" (Size) was statistically significant in AR and VA for E10. Consistent with expectations, as the number of people in the household increased, individuals were less likely to use biofuel blends. For E85, Size was statistically significant only in AR, where the results showed that an increase in number of people in the household would decrease the utility of individuals. Being the "head of the household" (Head) was significant in FL for E10 and AR and FL for E85. Heads of household were not likely to choose E85 in AR and FL or E10 in VA. Finally, the effect of unobservable influences was statistically significant in all three states for E10 and in VA and AR for $E 85$. Further, respondents were not likely to pay a premium for E85 in AR and in FL for E10.

\section{Willingness to Pay (WTP)}

The estimates of WTP a price premium for biofuels are shown in Table 9. The greatest WTP for E10 was in FL $\left(\$ 0.58\right.$ gallon $\left.^{-1}\right)$, followed closely by AR $\left(\$ 0.56\right.$ gallon $\left.^{-1}\right)$, 
Table 9 WTP $\left(\$\right.$ gallon $\left.^{-1}\right)$ for biofuels at state level

\begin{tabular}{llll}
\hline Blend & AR & FL & VA \\
\hline E10 & 0.56 & 0.58 & 0.50 \\
E85 & 0.82 & 1.17 & 1.06 \\
\hline
\end{tabular}

and VA $\left(\$ 0.50\right.$ gallon $\left.^{-1}\right)$. Similar findings were obtained by Bhattacharjee and others (2008), who calculated a mean WTP of $\$ 0.49$ gallon $^{-1}$ for $E 10$ in a U.S. nationwide study. We found that the mean WTP for E85 was 1.46, 2.00 and 2.1 times greater than for $E 10$ in AR, FL and VA, respectively. Three multiple comparison tests (Bonferroni, Scheffe and Sidak tests) were performed to detect differences in WTP among the three states for both blends. For E10 there were no significant differences in WTP among the three states. For E85 there were significant differences in the WTP between AR and FL and between AR and VA. However, there were no significant differences in the WTP between FL and VA.

The average prices of $E 85$ when the questionnaire was administered were $\$ 2.52$ gallon $^{-1}, \$ 3.00$ gallon $^{-1}$, and $\$ 3.07$ gallon $^{-1}$ in AR, FL, and VA, respectively (E85 Price Archives 2009). As noted earlier, average gasoline prices were $\$ 3.13$ gallon $^{-1}, \$ 3.21$ gallon $^{-1}$, and $\$ 3.69$ gallon $^{-1}$ for the same states. Thus, the ratios of WTP to actual E85 price were 1.57, 1.46, and 1.54 in AR, FL, and VA, respectively, averaging 1.52 . On the other hand, assuming the current price of gasoline as a proxy for E10, the ratios were much lower: 1.18, 1.18, and 1.13 in AR, FL, and VA, respectively, averaging 1.16. The ratios for both blends might be higher in the future, as market prices for gasoline and $E 85$ are expected to increase. Gasoline is predicted to have an annual price increase of $1.4 \%$ reaching $\$ 4$ gal$\operatorname{lon}^{-1}$ (2007 dollars) in 2030, while the annual price increase of $E 85$ will be $0.5 \%$ over the same period, reaching less than $\$ 3$ gallon $^{-1}$ (EIA 2008a).

Respondents were willing to pay more for biofuels if the proposed change offered better conditions for the environment. In VA, the state with the lowest WTP, respondents appeared to believe that the environmental improvements would not compensate for the premium for E10. VA's respondents, however, had the second greatest WTP $\left(\$ 1.06\right.$ gallon $\left.^{-1}\right)$ for $E 85$. Although the percentage of respondents rejecting the premiums were almost the same for both blends in VA (Figs. 1, 2), a larger percentage rejected the higher premiums. For example, for premiums of $\$ 0.75$ gallon $^{-1}$ and $\$ 1$ gallon $^{-1}, 65$ and $67 \%$ respondents rejected the purchase of $E 10$, whereas in the case of $E 85,55$ and $62 \%$ rejected premiums of $\$ 1$ gallon $^{-1}$ and $\$ 1.5$ gallon $^{-1}$, respectively. Further, the ratios of no versus yes responses to the premiums were 1.86 and 2.03 for E10 and 1.22 and 1.63 for $E 85$.
The WTP for price premiums for ethanol was converted into total future expenditures per year $\left(\mathrm{TE}_{\mathrm{e}}\right)$ by multiplying the total WTP by the quantity of gallons of ethanol $\left(\mathrm{Q}_{\mathrm{e}}\right)$ consumed as a proportion of total fuel consumption in the next period compared to the previous one (Solomon and Johnson 2009). This proportion is equal to the price elasticity of demand for biofuels $\left(\operatorname{Ed}_{\mathrm{e}}\right)$. The average per capita motor gasoline expenditures in 2006 (EIA 2008b) were used to calculate the quantity of gallons of ethanol. The real motor gasoline expenditures $(2007=100)$ accounted for $\$ 1,295, \$ 1,200$, and $\$ 1,373$ per capita in AR, FL, and AK, respectively. The total WTP can be separated into an average price of gasoline $\left(\mathrm{P}_{\mathrm{g}}\right)$ and the mean WTP for ethanol in each state $\left(\mathrm{WTP}_{\mathrm{e}}\right)$. Formally:

$T E_{e}=\left(P_{g}+W T P_{e}\right) Q_{e} * E d_{e}$

The mean total expenditures for $E 10$ were $\$ 585.20$, $\$ 485.90$, and $\$ 596.20$ per capita year ${ }^{-1}$ in AR, FL, and VA, respectively. For E85 the total expenditures were $\$ 919.60, \$ 330.80$, and $\$ 532.60$ per capita year ${ }^{-1}$. With the exception of E85 in AR, the results are similar to those found by Solomon and Johnson (2009). They reported a mean total future expenditure between \$252-\$556 per capita year ${ }^{-1}$ in Michigan, Minnesota, and Wisconsin. The ratios of total expenditures of E85 to E10 were 1.57, 0.68 , and 0.93 in AR, FL, and VA, respectively. The price elasticity of the demand was relatively inelastic $\left(-1<\operatorname{Ed}_{\mathrm{e}}<0\right)$ for both blends in the three states. The values for $\mathrm{Ed}_{\mathrm{e}}$ for $E 10$ were $-0.38,-0.34$, and -0.38 in $\mathrm{AR}, \mathrm{FL}$, and VA, respectively, while those for $E 85$ were $-0.56,-0.2$, and -0.31 . In general, the $E \mathrm{~d}_{\mathrm{e}}$ for $E 85$ was less elastic for E85 than E10, with the exception of AR, where the total expenditures for Arkansans were higher.

\section{Conclusions}

This article reported the findings of a choice experiment designed to elicit WTP and public preferences for E10 and E85 in AR, FL, and VA. We found that individuals had a positive WTP for price premiums for both blends. WTP was higher for biofuels that led to environmental improvements. No significant differences were found in the WTP among the three states for E10. For E85, significant differences were found between $\mathrm{AR}$ and FL and between $\mathrm{AR}$ and VA. The WTP ratios of E85 to E10 were 1.46, 2.00, and 2.12 for AR, FL, and VA, respectively. Thus, consumers in the U.S. south appeared to value the environmental benefits obtained from a modified transportation fuel. Converting WTP into future total expenditures produced ratios of total expenditures on E85 to E10 of 1.57, 0.68 , and 0.93 in AR, FL, and VA, respectively. With the exception of AR, total future expenditures were higher for 
E10 because of a more elastic price elasticity of the demand.

Our study also suggested that preferences for environmental attributes were heterogeneous. Respondents indicated to be willing to pay a premium for $E 10$ in order to achieve $\mathrm{CO}_{2}$ reduction in all three states and for biodiversity improvement in AR and FL. However, in all three states, results were opposite for improved biodiversity associated with E85. This heterogeneity was also observed in some socioeconomic variables. For example, only individuals with higher levels of education indicated willingness to purchase E10 in FL and E85 in AR. The high oil prices at the time of the survey and the higher premium proposed for E85 might explain why individuals from middle and high income households in AR and VA were reluctant to pay more for that biofuel.

Understanding present and future individual preferences for bioenergy is an important tool for policymakers. Our results support the initiation of a consistency policy instrument such as the Renewable Fuel Standard (RFS), aiming to produce 15.2 billion gallons of renewable fuels by 2012. However, it also underscores the need for federal or state governments to continuously reinforce in consumers the environmental benefits associated with biofuels. Although we find that individuals are willing to pay a premium for biofuels, periodic revisions of these studies are needed to ensure policies reflect changing public perceptions and preferences. The research could be extended in several ways. For example, different approaches might be used to allow welfare measures to be adjusted for different policy contexts. Meta analysis could also be used to validate and explore the systematic and identifiable variation of WTP to determine its appropriateness for benefits transfer. Finally, we assumed that people's preferences were homogeneous within each state. However, if people's choices are influenced by different geographical locations or other variables a more specific level of aggregation or an incorporation of spatial variation could be a plausible extension of this study.

Acknowledgments The authors would like to thank the two anonymous reviewers for their valuable comments and contribution to our article. This research was made possible by the financial support from the U.S. Department of Energy (DOE) and United States Department of Agriculture (USDA) through Biomass Research and Development Initiative.

\section{References}

Agee J, Bahro B, Finney M, Omi P, Sapsis D, Skinner C, Van Wagtendonk J, Weatherspoon C (2000) The use of shaded fuelbreaks in landscape fire management. Forest Ecology and Management 127:55-66
Aguilar F, Vlosky R (2007) Consumer willingness to pay price premiums for environmentally certified wood products in the USA. Forest Policy and Economics 9:1100-1112

Banzhaf S, Burtraw D, Evans D, Krupnick A (2006) Valuation of natural resource improvements in the Adirondacks. Land Economics 82(3):445-464

Belanger R, Hedden R, Lorio P (1993) Management strategies to reduce losses from the southern pine beetle. Southern Journal of Applied Forestry 17:150-154

Bergmann A, Hanley N, Wright R (2006) Valuing the attributes of renewable energy investments. Energy Policy 34(9):1004-1014

Berrens R, Bohara A, Jenkins-Smith H, Silva C, Weimer D (2004) Information and effort in contingent valuation surveys: application to global climate change using national internet samples. Journal of Environmental Economics and Management 47(3):331-363

Besanko D, Gupta S, Jain D (1998) Logit demand estimation under competitive pricing behavior: an equilibrium framework. Management Science 44(11):1533-1547

Bhattacharjee S, Petrolia D, Herndon C (2008) Estimating willingness to pay for E10 fuel: a contingent valuation method. In: Southern Agricultural Economics Association annual meeting, Dallas, TX, February 2-5, 2008

Borjesson P (2000) Economic valuation of the environmental impact of logging residue recovery and nutrient compensation. Biomass and Bioenergy 19:137-152

Carlsson F, Frykblom P, Liljenstolpe C (2003) Valuing wetland attributes: an application of choice experiments. Ecological Economics 47(1):95-103

Carlsson F, Frykblom P, Lagerkvist C (2005) Using cheap talk as a test of validity in choice experiments. Economics Letters 89(2):147-152

Champ P (2003) Collecting survey data for nonmarket valuation. In: Champ P, Boyle K, Brown T (eds) A primer on nonmarket valuation. Kluwer, Dordrecht, pp 59-98

Cochrane M, Schulze M (1999) Fire as a recurrent event of the Eastern Amazon: effects on forest structure, biomass, species composition. Biotropica 31(1):2-16

Cook J, Beyea J, Keeler K (1991) Potential impacts of biomass production in the United States on biological diversity. Annual Review of Energy and the Environment 16:401-431

Coulson R, Stephen F (2006) Impacts of insects in forest landscapes: implications for forest health management. In: Payne $\mathrm{T}$ (ed) Invasive forest insects, introduced forest trees, and altered ecosystems: ecological pest management in global forests of a changing world. Springer, New York 189 pp

Cummings RG, Taylor LO (1999) Unbiased value estimates for environmental goods: a cheap talk design for the contingent valuation method. American Economic Review 89:649-665

Dawson T, Butt N, Miller F (2001) The ecology of forest fires. ASEAN Biodiversity 1(3):18-21

Dijkstra S, Van Der Sijde P, Van Hout Wolters B (1990) Research on instruction: design and effects. Educational Technology Publications Inc, Englewood Cliffs 196 pp

Domac J, Richards K, Risovic S (2005) Socio-economic drivers in implementing bioenergy projects. Biomass and Bioenergy 28:97-106

E85 Price Archives (2009) http://e85prices.com/archive.php. Accessed 25 July 2009

Energy Information Administration (EIA) (2007) Annual energy outlook 2007 with projections to 2030. US Department of Energy DOE/EIA-0383(2007), Washington

Energy Information Administration (EIA) (2008a) Annual energy review 2007. US Department of Energy DOE/EIA-0384(2007), Washington 
Energy Information Administration (EIA) (2008b) State energy data 2005: prices and expenditures. http://www.eia.doe.gov/emeu/ states/sep_sum/html/pdf/rank_pr_mg.pdf. Accessed 10 July 2009

Energy Information Administration (EIA) (2009) Annual energy review 2008. US Department of Energy DOE/EIA-0384(2008), Washington

Evans M (1998) The economic impact of the demand for ethanol. Diane Publishing Company, Darby $49 \mathrm{pp}$

Farnsworth A, Summerfelt P, Neary D, Smith T (2003) Flagstaff's wildfire fuels treatments: prescriptions for community involvement and a source of bioenergy. Biomass and Bioenergy 24: 269-276

Fettig C, McMillin J, Anhold J, Hamud S, Borys R, Dabney C, Seybold S (2006) The effects of mechanical fuel reduction treatments on the activity of bark beetles (Coleoptera: Scolytidae) infesting ponderosa pine. Forest Ecology and Management 230(1-3):55-68

Flemming C, Bowden M (2007) Web-based surveys as an alternative to traditional mail methods. Journal of Environmental Economics and Management 90(1):284-292

Gan J (2007) Supply of biomass, bioenergy, and carbon mitigation: method and application. Energy Policy 35(12):6003-6009

Gan J, Smith C (2007) Co-benefits of utilizing logging residues for bioenergy production: the case for East Texas, USA. Biomass and Bioenergy 31(9):623-630

Haab T, McConnell K (2002) Valuing environmental and natural Resources: the econometrics of non market valuation. Edward Elgar Publishing, Northampton $326 \mathrm{pp}$

Hanemann W (1984) Welfare evaluations in contingent valuation experiments with discrete responses. American Journal of Agricultural Economics 66(3):332-341

Hettinga W, Junginger H, Dekker S, Hoogwijk M, McAloon A, Hicks $\mathrm{K}$ (2009) Understanding the reductions in US corn ethanol production costs: an experience curve approach. Energy Policy 37(1):190-203

Hill J, Nelson E, Tilman D, Polasky S, Tiffany D (2005) Environmental, economic, and energetic costs and benefits of biodiesel and ethanol biofuels. Proceedings of the National Academy of Sciences 103(30):11206-11210

Huggins V, Dennis M, Seryakova K (2002) An evaluation of nonresponse bias in internet surveys conducted using the knowledge networks panel. In: Annual Meeting of the American Statistical Association, Joint statistical meeting, New York, August 11-15, 2002

Kuhfeld W (2005) Marketing research methods in SAS. SAS Institute Inc, Cary, $857 \mathrm{pp}$

List JA (2001) Do explicit warnings eliminate the hypothetical Bias in elicitation procedures? evidence from field auctions for sports cards. American Economic Review 91:1498-1507

Manfreda K (2001) Web survey errors. PhD dissertation, University of Ljubljana

Manley A, Richardson J (1995) Silviculture and economic benefits of producing wood energy from conventional forestry systems and measures to mitigate negative impacts. Biomass and Bioenergy 9(1-5):89-105

Marta-Pedroso C, Freitas H, Domingos T (2007) Testing for the survey mode effect on contingent valuation data quality: a case study of web based versus in-person interviews. Ecological Economics 62(3-4):388-398

Mcfadden D (1974) Conditional logit analysis of qualitative choice behavior. In: Zarembka $\mathrm{P}$ (ed) Frontiers in econometrics. Academic Press, New York

Menegaki A (2008) Valuation for renewable energy: a comparative review. Renewable and Sustainable Energy Reviews 12(9): 2422-2437
Menges R, Schroeder C, Traub S (2005) Altruism, warm glow and the willingness-to-donate for green electricity: an artefactual field experiment. Environmental and Resource Economics 31:431-458

Mogas J, Riera P, Bennet J (2006) A comparison of contingent valuation and choice modelling with second-order interactions. Journal of Forest Economics 12(1):5-30

Neary D, Zieroth E (2007) Forest bioenergy system to reduce the hazard of wildfires: White Mountains, Arizona. Biomass and Bioenergy 31:638-645

Perlack R, Wright L, Turhollow A, Graham R, Strokes B, Erbach D (2005) Biomass as feedstock for a bioenergy and bioproducts industry: the technical feasibility of a billion ton annual supply. US Department of Agriculture and U.S. Department of Energy, Oak Ridge National Laboratory Technical Report ORNL/TM2005/66, OAR Ridge, TN

Pimentel D, Patzek T (2005) Ethanol production using corn, switchgrass, and wood; biodiesel production using soybean and sunflower. Natural Resources Research 14(1):65-76

Polagye B, Kevin T, Hodgson K, Malte P (2007) An economic analysis of bio-energy options using thinnings from overstocked forests. Biomass and Bioenergy 31:105-125

Renewable Fuel Association (2008) Will the plunge in grain prices mean lower food prices at the supermarket? Renewable fuel association report. http://www.ethanolrfa.org/objects/documents/ 1945/will_the_plunge_in_grain_prices_mean_lower_food_prices_ at_the_supermarket.pdf. Accessed 30 June 2009

Richardson J (2006) Sustainable production systems for bioenergy: impacts on forest resources and utilization of wood for energy. Biomass and Bioenergy 30:279-280

Roe B, Teisl M, Levy A, Russell M (2001) US consumers' willingness to pay for green electricity. Energy Policy 29(11): 917-925

Runkle J (1985) Disturbance regimes in temperate forests. In: Pickett S, White P (eds) The ecology of natural disturbances and patch dynamics. Academic Press, Orlando, pp 17-33

Secretariat of the Convention on Biological Diversity (2001) Impacts of human-caused fires on biodiversity and ecosystem functioning, and their causes in tropical, temperate and boreal forest biomes. Convention on biological diversity technical series no. 5 , Montreal

Shrestha R, Alavalapati J (2004) Valuing environmental benefits of silvopasture practice: a case study of the Lake Okeechobee Watershed in Florida. Ecological Economics 49(3):349-359

Simberloff D (1999) The role of science in the preservation of forest biodiversity. Forest Ecology and Management 115(2-3): 101-111

Solomon B, Johnson N (2009) Valuing climate protection through willingness to pay for biomass ethanol. Ecological Economics 68(7):2137-2144

Solomon B, Barnes J, Halvorsen K (2007) Grain and cellulosic ethanol: history, economics, and energy policy. Biomass and Bioenergy 31(6):416-425

Speight M (1997) Forest pests in the tropics: current status and future threats. In: Watt A, Stork N, Hunter M (eds) Forests and insects. Chapman and Hall, London 406 pp

Susaeta A, Alavalapati J, Carter D (2009) Modeling impacts of bioenergy markets on nonindustrial private forest management in the southeastern United States. Natural Resource Modeling 22(3):345-369

Urbanchuk J (2007) The relative impact of corn and energy prices in the grocery aisle. LECG report. http://www.ethanol.org/pdf/ contentmgmt/Impact_of_Corn_and_Energy_Prices_in_the_Grocery_ Aisle_June_07.pdf. Accessed 30 June 2009

US House of Representatives (1978a) Energy Tax Act of 1978. Public Law 95-618, 92 Stat. 3174 
US House of Representatives (1978b) Tax Reform Act of 1984. Public Law 98-369, 98 Stat. 494

US House of Representatives (1980) Omnibus Reconciliation Act of 1980. Public Law 96-499, 94 Stat. 2599

US House of Representatives (1990) Clean Air Act Amendments of 1990. Public Law 101-549, 104 Stat. 2399

US House of Representatives (1992) Energy Policy Act of 1992. Public Law 102-4864, 106 Stat. 2776

US House of Representatives (1998) Transportation Efficiency Act of the 21st Century. Public Law 105-178, 112 Stat. 107

US House of Representatives (2000) Biomass Research and Development Act of 2000. Public Law 106-224, 114 Stat. 428

US House of Representatives (2002) Farm Security and Rural Investment Act of 2002. Public Law 107-171, 116 Stat. 134

US House of Representatives (2003) Healthy Forests Restoration Act of 2003. Public Law 108-148, 117 Stat. 1887

US House of Representatives (2004) American Job Creation Act of 2004. Public Law 108-357, 118 Stat. 1418
US House of Representatives (2005) Energy Policy Act of 2005. Public Law 109-58, 119 Stat 594

US House of Representatives (2007) Energy Independence and Security Act of 2007. Public Law 110-140, 121 Stat. 1492

US House of Representatives (2008) Food, Conservation, and Energy Act of 2008. Public Law 110-234, 122 Stat. 923

Wang M (2005) The debate on energy and greenhouse gas emissions. Impacts of fuel ethanol. Center for Transportation Research, Energy Systems Division, Argonne National Laboratory Seminar Argonne National Laboratory August 3, 2005. http://www. transportation.anl.gov/pdfs/TA/347.pdf. Accessed 3 December 2009

Wang M, Sarick C, Santini D (1999) Effects of fuel ethanol use on fuel cycle energy and greenhouse gas emissions. Center for Transportation Research, Energy Systems Division, Argonne National Laboratory ANL/ESD-38, Argonne 